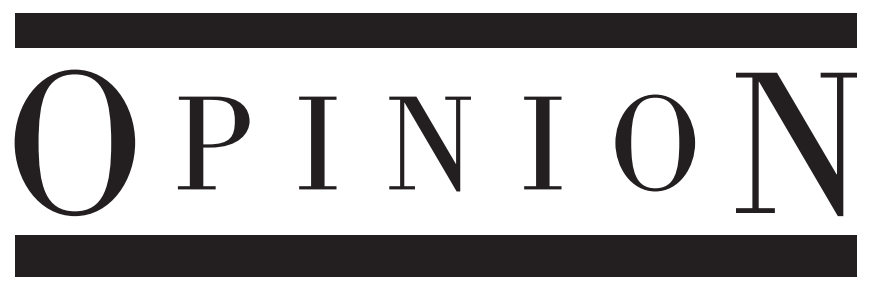

\section{On Operational Earthquake Forecast and Prediction Problems}

In his SSA presidential address (Jordan, 2014), and later in a more extended publication with coauthors (Jordan et al., 2014), Jordan presents a vision of forecast and prediction problems of earthquake system science. As experienced practitioners and in full appreciation of scientific studies on earthquake forecasting, we find it necessary to share a complementary viewpoint.

Eight decades ago, Richter (1935) introduced the logarithmic scale for sizing earthquakes, in full appreciation of the observed multiplicative scaling of energy liberated in a seismic event, inspired from the first statistics of the frequency of shocks of various magnitudes in southern California. In the 1960s, Edward Lorenz discovered deterministic chaos in a system of ordinary differential equations describing natural processes, Leon Knopoff demonstrated that a simple system of interacting elements may reproduce a complex "seismic" sequence, and Vladimir Keilis-Borok posed the problem of seismology and logics. In the 1970s, Israel Gelfand and John Tukey independently created a culture of exploratory data analysis that permits overcoming (though not completely) the com-
Jordan (2014) writes "forecasting and prediction are all about probabilities," although those probabilities are mixed with the deep uncertainties intrinsic to the natural earthquake generating system. perimental real-time mode "so that the ultimate success or failure of the prediction can readily be judged" (Allen et al., 1976, p. 7). It is undebatable that "Only by careful recording and analysis of failures as well as successes can the eventual success of the total effort be evaluated and future directions charted" (Allen et al., 1976, p. 7). A desirable confidence level assigned to prediction may arise from a subjective judgment of an expert (probability concept) or an objective score achieved in a real-time testing (experiment concept).

Jordan (2014) writes "forecasting and prediction are all about probabilities," although those probabilities are mixed with the deep uncertainties intrinsic to the natural earthquake generating system. Such uncertainties are naturally transferred as epistemic (systematic, due to a model neglecting certain effects) and aleatory (statistical, due to random noise effects) uncertainties in theoretical and/or computer modeling. Variability in an observable parameter of certain physical dimension cannot be expressed just by dimensionless level of probability (a number from 0 to 1). On the other hand, ground-motion models of neodeterministic seismic-hazard analysis (NDSHA) "can be combined to generate site-specific hazard curves, the main forecasting tool of probabilistic seisplexity of a process by robust representation of information and exhaustive numerical tests validating the results. By the 1980s, the lithosphere of the Earth was recognized as a complex hierarchically self-organized nonlinear dissipative system with critical phase transitions through larger earthquakes (Keilis-Borok, 1990). Mathematically, such chaotic systems are predictable-but only up to a limit and after substantial averaging: a success in forecasting catastrophic earthquakes implies a holistic approach, "from the whole to details." The problem of prediction is posed then as a successive step-by-step narrowing of the magnitude range of incipient earthquake, territory, and time interval. Otherwise, an attempt of shooting a silver bullet that pinpoints the magnitude, source, and time of future earthquake with a nearly exact precision would usually fail except for a rare case of random coincidence, a rather common case of "shoot first then draw the target" (Peresan and Panza, 2012), or both.

An objectivist understanding of the earthquake forecast and prediction problem is naturally expressed in empirical mathematically routed models and/or computer codes. "The proof of the pudding is in the eating": practitioners subject their forecasting tools to rigid testing, first in retrospect, and then in an ex- mic-hazard analysis (PSHA)" (Jordan, 2014, p. 767). In fact, large ensembles of deterministic simulations are feasible to achieve (e.g., Panza et al., 2001, 2012; see www.xeris.it; last accessed January 2015 for NDSHA code version on cloud platform), and statistics allow for probabilistic estimates of expected consequences needed for the implementation of riskmitigation actions. NDSHA is based on well-defined physical assumptions and makes use of interdisciplinary data from geomorphology, geologic, tectonic, and seismic studies, as well as from exploratory data analysis (Panza et al., 2012, and references therein). Seismology and computer science are not enough for a successful collaboration aimed at effective forecasting of larger earthquakes.

Getting experimentally reasonable confidence limits on an objective estimate of the recurrence rate of an earthquake requires a geologic span of time that is unreachable for instrumental, or even historical, seismology (e.g., Beauval et al., 2008). Consequently, probability estimates in PSHA remain subjective values from 0 to 1 , derived from analytically tractable hypothetical models of seismicity. In fact, PSHA is based on a subjective deterministic choice from a wide list of prob- 
abilistic models (e.g., http://www.cseptesting.org/centers/ scec; last accessed December 2014).

For decades, practitioners of deterministic earthquake prediction have made use of clustering in seismic sequences observed at different magnitude-space-time scales. For example, the M8 algorithm (Keilis-Borok and Kossobokov, 1990) diagnoses the time of increased probability (TIP) from multiparametric analysis of a dynamical system in its traditional phase space of rate and rate differential, supplemented with earthquake-specific measures of earthquake source concentration and clustering. Even if Harte $e t$ al. (2003) had compiled a probabilistic version of the M8 algorithm, as objectivist practitioners, we never provide probability value, but diagnose probability increases above the level sufficient for efficient prediction, although the counts used for diagnosis permit different choices when reporting results as a number in the $0-1$ range.

Jordan et al. (2014, their fig. 1) limit the scheme of operational earthquake forecasting (OEF) to "Earthquake" input and "Probabilistic" forecast and prediction. In our opinion, more input boxes with Global Positioning System, gravity, electromagnetic, geochemical, and other reliable geophysical information would allow for a true multidisciplinary forecast and prediction, which is so badly needed in risk analysis and mitigation. Forecasting information must be reliable, tested, confirmed by evidence, and not necessarily probabilistic. Naturally, the scheme applies to other natural hazards and can be further generalized.

Practitioners are positive that any reliable forecasting information can be (1) effective, (2) complementary to design and construction of seismically resistant infrastructure, and (3) well appreciated by population as a timely, precautious reminder and warning. The problem is whether or not short-term forecasting, in particular, the one expressed in extremely uncertain values of probability and magnitude range, is reliable. Wang and Rogers (2014) believe that it is not due to just a few mitigation measures doable in a day. Obviously, the spectrum of doable low-key preparedness options increases in cases of longer-term rather than short-term warnings.

Therefore, as objectivist practitioners, we advise decision makers to use the full, very broad spectrum of possible actions, following a general strategy of response to predictions by escalation or deescalation of safety measures and depending on expected losses and magnitude-space-time accuracy of reliable forecasting. The theoretical framework for the optimal choice of disaster preparedness measures undertaken in response to reliable forecast and prediction was suggested by Leonid Kantorovich, the 1975 Nobel Laureate in Economics (Kantorovich et al., 1974; Kantorovich and Keilis-Borok, 1991). As exemplified by Davis et al. (2012), the accuracy of reliable intermediate-term middle-range forecasting tools is sufficient for efficiently undertaking earthquake preparedness measures. Specifically, possible scenarios are used to illustrate how the prediction of an incipient great earthquake in the area covering northern Honshu and Hok- kaido could have been utilized during its timeframe (from mid-2001 to 2011) to reduce significant damage, including damage to the Fukushima nuclear power plant. Such scenarios show that prudent cost-effective actions can be taken if the prediction certainty is known, but not necessarily high.

In the existing practice of OEF based on NDSHA for Italy, maps of ground-motion parameters expected from scenario earthquakes in the areas of current TIPs have been routinely provided to Protezione Civile della Regione Autonoma Friuli Venezia Giulia (PC-FVG) as bimonthly reports since 2005 (Panza et al., 2013, 2014). This practice follows the two basic principles of transparency and hazard-risk separation recommended by the International Commission on Earthquake Forecasting for Civil Protection (Jordan et al., 2011). The series of NDSHA maps are well appreciated as handy information by PC-FVG, who retain the responsibility of independent professional assessment and mitigation of seismic risks in the region. PC-FVG shares our opinion that bimonthly reports with maps of ground shaking expected in the nearest future are very helpful for operational planning and sizing of emergency resources and preparedness, as confirmed by direct interest in getting this OEF information (DGR-2226dd14.09.2005 and DGR1459dd24.6.2009, in which DGR is Delibera della Giunta Regionale [i.e., resolution of the Regional Council], 2226 is resolution number, and dd14.09.2005 is day of approval of the resolution; http://www.regione.fvg.it/rafvg/cms/ RAFVG/; last accessed October 2014). In our opinion, mapping a number in the 0-1 range (either with or without thresholds that, according to Jordan et al., 2014, p. 957, "need to be negotiated among the stakeholders in a specific user group, not imposed by OEF across user groups") is less informative for a decision maker than a series of maps of the ground-motion parameters expected to happen soon.

The OEF information to PC-FVG (e.g., Panza et al., 2014) is not distracting. Rather it may enhance preparedness of population in the areas of TIPs, where "alerts of increased probabilities during such periods can serve as reminders to all residents of earthquake country that long-term mitigation measures must be enacted to ensure their safety" (Jordan et al., 2014, p. 957). The decades-long experience shows in practice that OEF is also not dangerous, when viewed as the PC-FVG routine escalation and de-escalation of professionally appropriate timely warnings, starting from the longterm ones.

Objectivist practitioners know firsthand that probability estimates and OEF models are testable and continuously use probability estimates, for example, to quantify the performance of forecast and prediction models. As examples of OEF, Jordan et al. (2014) mention the short-term earthquake probability (STEP) model, in which poor performance could have been anticipated 
before publication in Nature (Gerstenberger et al., 2005), and starting up the U.S. Geological Survey site, which shows daily ground-shaking probabilities in California. Based on the 15 years of seismic record statistics from Gerstenberger et al. (2005), Kossobokov $(2005,2006)$ presented a half-page proof that suggests rejecting (with confidence above $97 \%$ ) the generic California clustering model used in calculation of forecasts of expected ground shaking for tomorrow. The poor performance of STEP was eventually confirmed (Kossobokov, 2008a,b): in 1060 days of the real-time forecasting, the five California earthquakes with modified Mercalli intensity (MMI) greater than or equal to VI occurred in the areas of the website's lowest risk (about 1/10,000 or less), whereas the extent of the observed areas of MMI VI for these events (about 100 cells in total) is, by far, less than the expected number of cells experiencing MMI $\geq$ VI (about 850 cells). "A site, showing daily ground-shaking probabilities in California, ... was subsequently removed because of coding problems" (Cartlidge, 2014, p. 6).

The first test results of short-term forecasting in various modifications accepted for testing in the framework of the Collaboratory for the Study of Earthquake Predictability (Jordan, 2006) are rather modest so far (http://www .cseptesting.org/documents/papers; last accessed December 2014) and may be reminiscent of the case of STEP. In the absence of an adequate probabilistic model, tested against solid observational evidence, any forecasting tool (with or without "a series of probability thresholds") remains a subjective deterministic prediction method of uncertain quality. Those who develop OEF systems should not overlook this basic concept. Communicating OEF and its uncertainties must be done with a keen feeling of responsibility for the final outcome in warning people of looming disaster. $\$$

\section{ACKNOWLEDGMENTS}

We thank J. Douglas Zechar, an anonymous reviewer, and the Editor for their valuable suggestions. We acknowledge financial support from Italian Dipartimento della Protezione Civile (Seismological Projects S3, 2012), Protezione Civile della Regione Autonoma Friuli Venezia Giulia and Provincia di Trieste. V. G. K. has been supported by the Russian Foundation for Basic Research (Grants RFBR 13-05-91167 and 14-05-92691).

\section{REFERENCES}

Allen, C. R., W. Edwards, W. J. Hall, L. Knopoff, C. B. Raleigh, C. H. Savit, M. N. Toksoz, and R. H. Turner (1976). Predicting earthquakes: A Scientific and Technical Evaluation-With Implications for Society, Panel on Earthquake Prediction of the Committee on Seismology, Assembly of Mathematical and Physical Sciences, National Research Council, US-NAS, Washington, D.C.

Beauval, C., P.-Y. Bard, S. Hainzl, and P. Guguen (2008). Can strong motion observations be used to constrain probabilistic seismic hazard estimates? Bull. Seismol. Soc. Am. 98, 509-520.
Cartlidge, E. (2014). A dangerous distraction? Phys. World 6-7.

Davis, C., V. Keilis-Borok, V. Kossobokov, and A. Soloviev (2012). Advance prediction of the March 11, 2011 Great East Japan earthquake: A missed opportunity for disaster preparedness, Int. J. Disaster Risk Red. 1, 17-32.

Gerstenberger, M., S. Wiemer, L. M. Jones, and P. A. Reasenberg (2005). Real-time forecasts of tomorrow's earthquakes in California, Nature 435, 328-331.

Harte, D., D.-F. Li, M. Vreede, and D. Vere-Jones (2003). Quantifying the M8 prediction algorithm: Reduction to a single critical variable and stability results, New Zeal. J. Geol. Geophys. 46, 141-152.

Jordan, T. H. (2006). Earthquake predictability, brick by brick, Seismol. Res. Lett. 77, 3-6.

Jordan, T. H. (2014). The prediction problems of earthquake system science, Seismol. Res. Lett. 85, 767-769.

Jordan, T. H., Y.-T. Chen, P. Gasparini, R. Madariaga, I. Main, W. Marzocchi, G. Papadopoulos, G. Sobolev, K. Yamaoka, and J. Zschau (2011). Operational earthquake forecasting: State of knowledge and guidelines for implementation, Final Report of the International Commission on Earthquake Forecasting for Civil Protection, Ann. Geophys. 54, 315391.

Jordan, T. H., W. Marzocchi, A. J. Michael, and M. C. Gerstenberger (2014). Operational earthquake forecasting can enhance earthquake preparedness, Seismol. Res. Lett. 85, 955-959.

Kantorovich, L. V., and V. I. Keilis-Borok (1991). Earthquake prediction and decision-making: Social, economic and civil protection aspects, in Proc. International Conference on Earthquake Prediction: State-of-the-Art, Scientific-Technical Contributions, CSEMEMSC, Strasbourg, France, 586-593 (based on Economics of earthquake prediction in Proc. UNESCO Conference on Seismic Risk, Paris, 1977).

Kantorovich, L. V., V. I. Keilis-Borok, and G. M. Molchan (1974). Seismic risk and principles of seismic zoning, in Seismic design decision analysis, internal study report, Department of Civil Engineering, Massachusetts Institute of Technology, $43 \mathrm{pp}$.

Keilis-Borok, V. I. (1990). The lithosphere of the Earth as a nonlinear system with implications for earthquake prediction, Rev. Geophys. 28, 19-34.

Keilis-Borok, V. I., and V. G. Kossobokov (1990). Premonitory activation of seismic flow: Algorithm M8, Phys. Earth Planet. Int. 61, 73-83.

Kossobokov, V. (2005). Regional earthquake likelihood models: A realm on shaky grounds? Eos Trans. $A G U \mathbf{8 6}$, no. 52, Fall Meet. Supplement Abstract S41D-08.

Kossobokov, V. G. (2006). Deception points of earthquake probability models, Geophys. Res. Abstr. 8, 04357.

Kossobokov, V. G. (2008a). Forecast and prediction of extreme events, Earthquake Seminars, 2008 Archives (22 December 2008), U.S. Geological Survey, Menlo Park, California, http://earthquake.usgs .gov/regional/nca/seminars/?year=2008 (last accessed January 2015).

Kossobokov, V. G. (2008b). Testing earthquake forecast/prediction methods: "Real-time forecasts of tomorrow's earthquakes in California," Geophys. Res. Abstr. 10, EGU2008-A-07826.

Panza, G. F., C. La Mura, A. Peresan, F. Romanelli, and F. Vaccari (2012). Seismic hazard scenarios as preventive tools for a disaster resilient society, Adv. Geophys. 53, 93-165.

Panza, G. F., A. Peresan, C. La Mura (2013). Seismic hazard and strong ground motion: An operational neo-deterministic approach from national to local scale, in Encyclopedia of Life Support Systems, Geophysics and Geochemistry, UNESCO-EOLSS Joint Committee (Editors), Eolss Publishers, Oxford, United Kingdom, 1-49.

Panza, G. F., A. Peresan, and A. Magrin (2014). Mem. Descr. Carta Geologica D'Italia, ISPRA Servizio Geologico D'Italia 94, 1-103, http://www.isprambiente.gov.it/it/pubblicazioni/periodici-tecnici 
/memorie-descrittive-della-carta-geologica-ditalia/scenari-neo -deterministici-di-pericolosita-sismica-per-il-friuli-venezia-giulia-e-le -aree-circostanti (last accessed January 2015).

Panza, G. F., F. Romanelli, and F. Vaccari (2001). Seismic wave propagation in laterally heterogeneous anelastic media: Theory and applications to seismic zonation, $A d v$. Geophys. 43, 1-95.

Peresan, A., and G. F. Panza (2012). Improving earthquake hazard assessments in Italy: An alternative to "Texas Sharpshooting", Eos Trans. $A G U$ 93, 538-539.

Richter, C. F. (1935). An instrumental earthquake magnitude scale, Bull. Seismol. Soc. Am. 25, 1-32.

Wang, K., and G. C. Rogers (2014). Earthquake preparedness should not fluctuate on a daily or weekly basis, Seismol. Res. Lett. 85, 569-571.

Vladimir G. Kossobokov ${ }^{I}$ Institute of Earthquake Prediction Theory and Mathematical Geophysics Russian Academy of Sciences 84/32 Profsoyuznaya Street 117997 Moscow, Russian Federation volodya@mitp.ru
Antonella Peresan ${ }^{2}$ G. F. Panza

Department of Mathematics and Geosciences University of Trieste

Via Weiss 4 34127 Trieste, Italy

aperesan@units.it panza@units.it

Published Online 25 February 2015

${ }^{1}$ Also at Abdus Salam ICTP, SAND Group, Trieste, Italy; at Institut du Physique du Globe (IPGP), Paris, France; and at International Seismic Safety Organization, ISSO (www.issoquake.org).

${ }^{2}$ Also at Abdus Salam ICTP, SAND Group, Trieste, Italy; and at International Seismic Safety Organization, ISSO (www.issoquake.org). 3 Also at Abdus Salam ICTP, SAND Group, Trieste, Italy; at International Seismic Safety Organization, ISSO (www.issoquake .org); and at IG, China Earthquake Administration, Beijing, PRC. 